\title{
VIEWPOINT
}

\section{Vitamin D in sepsis: from basic science to clinical impact}

\author{
Jordan A Kempker*1, Vin Tangpricha² ${ }^{2}$ Thomas R Ziegler ${ }^{3}$ and Greg S Martin'
}

\begin{abstract}
The growing basic and clinical investigations into the extraskeletal effects of vitamin $\mathrm{D}$ have revealed roles in the functioning of the immune system, generating interesting questions about this nutrient's connections to sepsis. This article briefly reviews the current science of the function of vitamin D in the immune system as well as the emerging clinical literature regarding its associations with respiratory infections, sepsis, and critical illness. Finally, we offer views on the potential future directions for research in the field by outlining potential relevant scenarios and outcomes.
\end{abstract}

With the discovery of the vitamin D receptor (VDR) and 25-hydroxyvitamin $\mathrm{D}-1 \alpha$-hydroxylase in many extraskeletal tissues and the vitamin D response element in over 900 genes, scientists are beginning to uncover that vitamin $\mathrm{D}$, a secosteroid hormone, may have roles in the optimal functioning of many organ systems and chronic illnesses [1-5]. The interest in vitamin D status was exemplified by the 2011 Institute of Medicine (IOM) report establishing a minimum serum 25 -hydroxyvitamin $\mathrm{D}(25(\mathrm{OH}) \mathrm{D})$ concentration of $20 \mathrm{ng} / \mathrm{mL}$ as the optimal level for skeletal health in the US [6] and the Endocrine Society recommendation of a concentration of at least $30 \mathrm{ng} / \mathrm{mL}$ for optimal health benefits [2]. The scope of this problem certainly affects the subset of patients with critical illness and sepsis, and recent reports show that $79 \%$ to $98 \%$ of intensive care unit (ICU) patients are vitamin D-insufficient [7-9].

\section{Vitamin D and immune function}

One of the most promising extraskeletal roles of vitamin $\mathrm{D}$ for patients with sepsis is in the functioning of the

\footnotetext{
*Correspondence: jkempke@emory.edu

'Division of Pulmonary and Critical Care Medicine, Emory University School of

Medicine, 49 Jesse Hill Jr. Drive SE, Atlanta, GA 30303, USA

Full list of author information is available at the end of the article
}

immune system (Table 1). This was initially indicated by the discovery of VDRs in nearly all types of immune cells [10], spanning the body's innate and adaptive immune responses to pathogens. Further studies have revealed that vitamin D modulates immune responses to the proinflammatory bacterial endotoxin (lipopolysaccharide) in vitro and in rodent models of sepsis [11-16] and shown evidence that vitamin $\mathrm{D}$ is involved in the monocyte response to Candida albicans [17].

In addition to affecting the humoral response to sepsis, vitamin $\mathrm{D}$ acts in the local tissue response to infection [18] and is integral to the production of antimicrobial peptides (AMPs) $[19,20]$. A landmark study by Liu and colleagues [21] in 2006 revealed the critical role of vitamin $\mathrm{D}$ in the macrophage response to Mycobacterium tuberculosis via the AMP cathelicidin. The active fragment of cathelicidin is LL-37, which has been shown to be produced by phagocytic leukocytes, mucosal epithelium, and keratinocytes and to be present in mucosal secretions and plasma [22]. Its immune functions include direct bactericidal activity as well as disruption of Pseudomonas aeruginosa biofilms, promotion of phagocytosis and reactive oxygen species, and chemotaxis of other immune cells to sites of infection [22]. These properties have been demonstrated to have efficacy in in vitro studies of human airway and bladder pathogens $[23,24]$.

Complementing the basic science research, clinical research has examined the role of vitamin $D$ in the prevention and control of respiratory infections, the most common source of sepsis in the US [25]. The clinical literature has a wide array of study designs, selected populations, and interventions and has demonstrated mixed results. Whereas observational studies among adults have revealed an association between low vitamin $D$ and the incidence of respiratory infections [26,27], clinical trials have not produced strong results $[28,29]$. Among children, observational studies examining the relationship between low vitamin $\mathrm{D}$ and respiratory infections have also shown varied results [3,30-34], yet in two intervention trials, vitamin $\mathrm{D}$ reduced rates of recurrence of respiratory infections at 3 months [35] and decreased the incidence of influenza A infection [36]. The 


\section{Table 1. Basic science research of the role of vitamin D in infection}

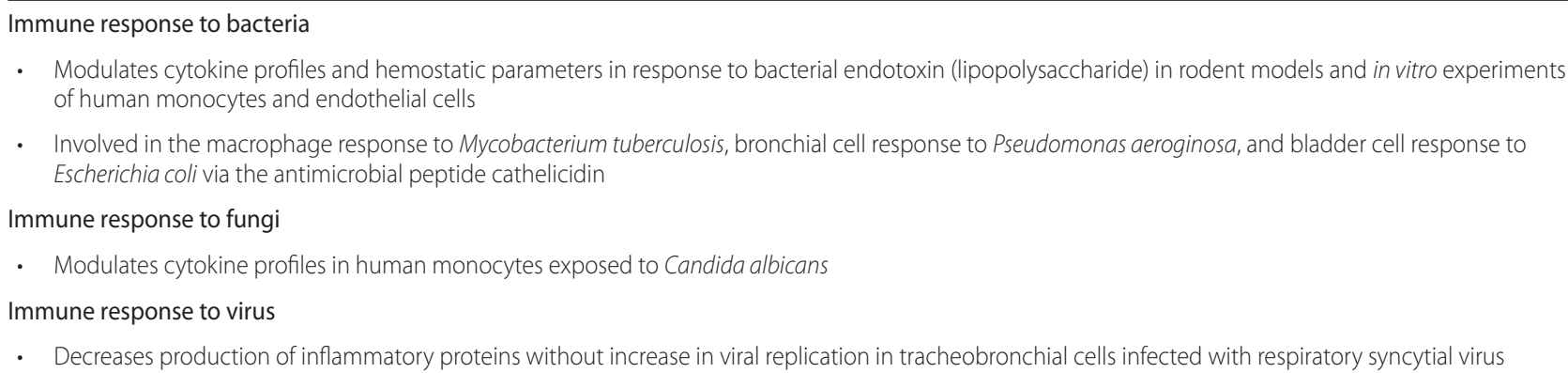

lessons from these early trials include the dosing to ensure vitamin D repletion, the need for larger sample sizes or higher-risk populations that may show larger effect sizes, and recognition of relevant short- and longterm endpoints. Given that a recent query of intervention trials on 'vitamin D' and 'infection' on ClinicalTrials.gov yielded 67 results, the picture of the role of vitamin D in infection will likely become clearer in the near future.

\section{Vitamin D in sepsis and critical illness}

Although infection is a necessary cause for sepsis, it is still uncertain whether vitamin D will have a clinically detectable effect on this common pathway with such a variety of infective antecedents that leave patients in extremis. Furthermore, the potential effects of vitamin D on other physiologic systems make it difficult to isolate its relationship to sepsis in the critically ill. In this population, the research examining the associations between vitamin $\mathrm{D}$ and hypocalcemia, bone resorption, insulin resistance, pulmonary function, and cardiovascular events may yet reveal therapeutic effects in critically ill and septic patients [4,5,37-42]. Although examining these topics is beyond the scope of this paper, they are important effects to consider in understanding the literature on vitamin $\mathrm{D}$ and sepsis.

Much of the current clinical science regarding vitamin $\mathrm{D}$ and sepsis is nested within the larger studies of critically ill patients. Studies examining vitamin D insufficiency and sepsis within critical illness have had mixed designs and results. One retrospective study of 136 veterans admitted to the ICU demonstrated a significantly increased survival rate (69\% versus $44 \%)$ among those with serum $25(\mathrm{OH}) \mathrm{D}$ concentrations of greater than $20 \mathrm{ng} / \mathrm{mL}$ [8]. A multicenter retrospective observational study of 2,399 medical and surgical ICU patients with serum 25(OH)D levels drawn within the year prior to admission showed an increase in all-cause mortality among vitamin D-insufficient and -deficient groups [43]. An analysis of the patients in this source population with a $25(\mathrm{OH}) \mathrm{D}$ concentration drawn within 7 days of ICU admission revealed similar results [44]. In either analysis, the presence of sepsis did not modify the association between vitamin $\mathrm{D}$ and mortality, but in the first study, a significant association between low serum 25(OH)D concentrations and an increase in blood culture positivity was found [43]. A retrospective study of 437 ICU patients showed similar findings, with a significant relationship between in-hospital mortality and vitamin D deficiency that was not influenced by any admission category, including sepsis [45]. In regard to the surgical ICU, a recent study of 66 patients found trends toward higher rates of infection and sepsis in those with a serum $25(\mathrm{OH}) \mathrm{D}$ concentration of less than $20 \mathrm{ng} / \mathrm{mL}$ [46].

In addition to this research in the larger population of the critically ill, investigation specifically examining vitamin D and sepsis has begun. However, this work is still in its early phases. All of the published literature in this area is observational but has revealed some interesting findings. In a prospective study of 92 patients with severe sepsis and septic shock in comparison with trauma patients, vitamin $\mathrm{D}$ was a predictor of mortality in the univariate analysis, yet the relationship became insignificant in the multivariate analysis [47]. Another study followed 81 patients suspected of an infection in the emergency department and found that patients with serum $25(\mathrm{OH}) \mathrm{D}$ concentrations of less than $30 \mathrm{ng} / \mathrm{mL}$ were more likely at enrollment and at 24 hours to have more occurrences of severe sepsis and organ dysfunction [48]. Our group found that, in ICU patients, serum LL-37 levels positively correlated with $25(\mathrm{OH}) \mathrm{D}$ concentrations and that vitamin D-binding protein (VDBP) was decreased in patients with sepsis in comparison with those without sepsis [11]. This raises new questions about the role of VDBP in mediating vitamin D responses in the ICU. Furthermore, it demonstrates how translational research designs can create a reciprocal dialogue between the basic and clinical sciences and may help drive research in this area.

In summary, the results of the clinical science of vitamin $\mathrm{D}$ and sepsis are mixed, yet it would be simplistic to dismiss this field of research on such grounds. The failure of vitamin $\mathrm{D}$ to produce effects in the current observational literature may be a result of study design and insufficient power to reveal a mortality difference. 
Table 2. Future research questions in vitamin $D$ and sepsis

Vitamin D and the burden of sepsis in the community

- What serum $25(\mathrm{OH}) \mathrm{D}$ concentration is optimal for immune function?

- Can vitamin D supplementation reduce the incidence of infection and progression to sepsis?

- Is vitamin D a causal factor of racial health disparities in sepsis?

- Is vitamin D a causal factor of the seasonal variations in infection and sepsis?

Vitamin D in the health-care setting

- Is serum $25(\mathrm{OH})$ D concentration a reliable measure of vitamin D in critical illness?

- Can acute vitamin D repletion alter the progression of sepsis and severity of organ dysfunction?

- Can vitamin D repletion reduce the incidence of hospital-acquired infections?

- What is a safe dosing schedule for rapid vitamin $D$ repletion and maintenance therapy in hospitalized patients?
Although the pluripotency of vitamin D sparks our interest for a treatment affecting sepsis mortality, it may be unrealistic to power a study to show such a difference. The results of the Cochrane review by Bjelakovic and colleagues [49], who demonstrated a vitamin D-induced $0.6 \%$ absolute reduction on all-cause mortality in the general population, would be challenging to translate to critically ill patients with sepsis. Even if the median follow-up time were disregarded, a clinical trial to detect a $0.6 \%$ mortality difference would require a sample size of over 100,000, even in low-mortality ICUs. Allocation of this enormous amount of resources for such a small effect size is not justifiable.

Trial design is not the only important challenge in studying vitamin D and sepsis. There are several issues regarding the measurement and interpretation of serum $25(\mathrm{OH}) \mathrm{D}$ in this population. Although the IOM report defined a $25(\mathrm{OH}) \mathrm{D}$ concentration of $20 \mathrm{ng} / \mathrm{mL}$ for skeletal health, we still do not know what level may be optimal for immune function [6]. Furthermore, it is still uncertain whether serum $25(\mathrm{OH}) \mathrm{D}$ is an appropriate measure for the effects of vitamin D on the immune system. With the abilities of immune cells to activate and concentrate vitamin $\mathrm{D}$, it is possible that low serum concentrations may be a signal of an activated immune system in the acute phase rather than a risk factor for impaired immunity. Even if serum measures were indicative of risk, another issue is the reliability of serum 25(OH)D concentrations in septic patients receiving fluid resuscitation. A study of cardiac surgery patients demonstrated that the hemodilutional effects of fluid resuscitation can decrease serum $25(\mathrm{OH}) \mathrm{D}$ concentration by up to $35 \%$ [50]. All of these issues present significant challenges that must be accounted for with intelligent trial design and data analysis.

\section{Future directions}

The challenges in the field of vitamin D and sepsis may seem daunting, but the basic and clinical data show promise. An interesting connection for future research is the association between vitamin $\mathrm{D}$ and the potential role of statins in treating sepsis [51]. Certain statins have been associated with increasing vitamin $\mathrm{D}$, and although a recent meta-analysis did not support their role in preventing infections, there is still potential for the use of statins during sepsis [51-53]. Furthermore, although it may be difficult to show mortality benefits in sepsis with vitamin D, work can proceed in investigating the facets of the relationship which are suggested by the basic sciences. Here, it seems that the data are strongest when showing that vitamin $\mathrm{D}$ has the potential to prevent infections, whether community- or hospital-acquired, and to diminish the severity of sepsis and consequent organ dysfunction. These realms open a wide array of clinical research questions (Table 2) that need to be addressed if we are to be successful in revealing the truth. In the planning of future research, it may be useful to conceptualize and test the potential roles of vitamin D as a 'primary prevention,' 'acute intervention', and 'secondary prevention'.

In the first hypothetical role, as a 'primary prevention', vitamin $\mathrm{D}$ may serve to help prevent infections and diminish the severity of sepsis in the community. This question lends itself to observational investigation, following cohorts prospectively when they come to medical attention or retrospectively in large administrative databases. Some interesting questions here are the potential causal role of vitamin $\mathrm{D}$ in the associations between African-American race and winter season on rates of infections and sepsis. In regard to race, studies have shown that, when compared with Caucasians, African-Americans are more likely to develop sepsis $[54,55]$, develop more infections [56], and have higher rates of organ dysfunction with sepsis [57]. Although vitamin D status was not included in these studies, African-Americans tend to have lower serum 25(OH)D concentrations than Caucasians [58], and this is explained in part by the fact that melanin absorbs the 
ultraviolet B light that produces vitamin D in skin [59]. Furthermore, in the US, there is a seasonal variation of respiratory infections and sepsis - namely higher incidences in the winter and the lower ones in the fall which is more pronounced in the Northeast [60]. These patterns parallel the annual variations in serum $25(\mathrm{OH}) \mathrm{D}$ concentrations, which peak in the fall and reach the lowest point after the winter and are also less pronounced closer to the equator [61]. Other than the confounders of age, sex, sun exposure, and socioeconomic status, an associated factor in these relationships may be obesity. Given the positive relationship between obesity and vitamin D deficiency as well as a concern for increased infection and inflammation in the obese, this may be a potential confounding or interacting factor in the relationship between vitamin D and sepsis [62]. These are interesting speculations that require the intensivist to expand the scope of research beyond the ICU to cohorts within the general population or those admitted to the hospital.

The second hypothetical role of vitamin D, as an 'acute pharmacologic intervention', is more familiar territory for intensivist investigators, yet research should still proceed with caution. Here, pilot dose-finding and clinical outcome data are needed to inform the design of rigorous intervention trials should pilot studies show potential benefits of vitamin D supplementation in ICU patients. In regard to potential toxicities of vitamin $\mathrm{D}$, there are not much data. Reports suggest frank toxicity with hypercalcemia at serum concentrations of greater than $200 \mathrm{ng} / \mathrm{mL}$; however, long-term studies of all-cause mortality suggest that vitamin D may show a reverse Jshaped curve in which mortality increases at concentrations of greater than 30 to $48 \mathrm{ng} / \mathrm{mL}$ [6]. For acute treatment, small trials of treatment in the ICU have shown that two doses of 60,000 IU or a single dose of 540,000 IU of oral vitamin $\mathrm{D}_{3}$ can rapidly and safely normalize serum $25(\mathrm{OH})$ concentrations [63,64]. Aside from the issue of toxicities, the therapeutic effects of vitamin $\mathrm{D}$ are most likely subtle and small and should be sought accordingly. Its low toxicity does not need a large beneficial effect for a therapeutic index to justify use. However, its potential pleiotropic effects in the critically ill population at large make identifying specific primary outcomes challenging. Potential sepsis-specific outcomes include progression and severity of sepsis and organ dysfunction. AMP concentrations in blood, bronchial fluid, and peripheral monocytes may be used as targets for identifying the mechanism of these effects. As growing basic science data clarify the relationships with the cardiovascular, respiratory, and endocrine systems, it may become scientifically valid to include other important endpoints for critical illness, such as ventilator and ICU days, lung injury scores, and vasopressor and insulin requirements. Consideration should also be given to using combined endpoints that group together the multiple potential measurable effects it may have on sepsis and the dysfunction of various organ systems. These outcomes are relatively specific to the ICU and the time a patient spends there, yet in designing these trials, investigators should keep in mind endpoints that encompass the third potential therapeutic role of vitamin $D$, as a 'secondary prevention'.

Repletion of vitamin D, in its capacity as a 'secondary prevention, on admission and maintenance therapy over time may serve to protect patients against hospitalacquired infections and recurrence of sepsis in vulnerable populations. This hypothetical role is similar to the role aspirin plays in acute coronary syndromes, for which patients who present with an index case are given a loading dose and then maintained on prolonged therapy to prevent recurrent events. Our group is currently collecting data on a medical ICU cohort to examine the relationship between plasma 25(OH)D concentration at ICU admission and the risk for hospital-acquired infections. We are also performing a pilot comparative effectiveness trial of various high-dose vitamin $D_{3}$ regimens in surgical ICU patients (ClinicalTrials.gov identifier NCT01372995).

Although basic science research suggests that vitamin D may have integral roles in the optimal functioning of the immune system, it is not clear whether correction of vitamin D depletion or optimization of vitamin D status or both are efficacious as an adjunctive therapy in the prevention or treatment of infection, particularly in critical care. However, known effects on multiple organ systems, including the immune system, suggest that research on the effects of vitamin D treatment may be promising. Emerging studies showing small or no effects of vitamin D treatment on mortality suggest that dose responses need to be carefully evaluated and clinical trials should be rigorous in order to evaluate the potential role of this nutrient in critical illness.

\section{Abbreviations}

25(OH)D, 25-hydroxyvitamin D; AMP, antimicrobial peptide; ICU, intensive care unit; IOM, Institute of Medicine; VDBP, vitamin D-binding protein; VDR, vitamin D receptor.

\section{Acknowledgments}

This work was supported in part by National Institutes of Health grants T32 AA013528 (JAK), R21 HL110044, K23AR054334 (VT), K24 RR023356 (TRZ), U54 RR-024380, and P50 AA-013757 (GSM) and the Atlanta Clinical and Translational Science Institute (UL1 RR025008).

\section{Author details}

'Division of Pulmonary and Critical Care Medicine, Emory University School of Medicine, 49 Jesse Hill Jr. Drive SE, Atlanta, GA 30303, USA. ${ }^{2}$ Division of

Endocrinology, Metabolism and Lipids, Emory University School of Medicine, 101 Woodruff Circle NE-WMRB1301, Atlanta, GA 30322, USA. ${ }^{3}$ Division of Endocrinology, Metabolism and Lipids, Emory University School of Medicine, 1364 Clifton Road Room GG-23, Atlanta, GA 30023, USA.

Published: 19 July 2012 


\section{References}

1. Wang TT, Tavera-Mendoza LE, Laperriere D, Libby E, MacLeod NB, Nagai Y, Bourdeau V, Konstorum A, Lallemant B, Zhang R, Mader S, White JH: Largescale in silico and microarray-based identification of direct

1,25-dihydroxyvitamin D3 target genes. Mol Endocrinol 2005, 19:2685-2695.

2. Holick MF, Binkley NC, Bischoff-Ferrari HA, Gordon CM, Hanley DA, Heaney RP, Murad MH, Weaver CM: Evaluation, treatment, and prevention of vitamin D deficiency: an Endocrine Society clinical practice guideline. J Clin Endocrinol Metab 2011, 96:1911-1930.

3. Yamshchikov AV, Desai NS, Blumberg HM, Ziegler TR, Tangpricha V: Vitamin D for treatment and prevention of infectious diseases: a systematic review of randomized controlled trials. Endocr Pract 2009, 15:438-449.

4. Sokol SI, Tsang P, Aggarwal V, Melamed ML, Srinivas VS: Vitamin D status and risk of cardiovascular events: lessons learned via systematic review and meta-analysis. Cardiol Rev 2011, 19:192-201.

5. Zhao G, Ford ES, Li C, Croft JB: Serum 25-hydroxyvitamin D levels and allcause and cardiovascular disease mortality among US adults with hypertension: the NHANES linked mortality study. J Hypertens 2012 30:284-289

6. Ross AC, Taylor CL, Yaktine AL, Del Valle HB (eds); Committee to Review Dietary Reference Intakes for Vitamin D and Calcium, Institute of Medicine: Dietary Reference Intakes for Calcium and Vitamin D. Washington, DC: National Academies Press; 2011

7. Lucidarme O, Messai E, Mazzoni T, Arcade M, du Cheyron D: Incidence and risk factors of vitamin $D$ deficiency in critically ill patients: results from a prospective observational study. Intensive Care Med 2010, 36:1609-1611.

8. McKinney JD, Bailey BA, Garrett LH, Peiris P, Manning T, Peiris AN: Relationship between vitamin D status and ICU outcomes in veterans. J Am Med Dir Assoc 2011, 12:208-211.

9. Jeng L, Yamshchikov AV, Judd SE, Blumberg HM, Martin GS, Ziegler TR, Tangpricha V: Alterations in vitamin D status and anti-microbial peptide levels in patients in the intensive care unit with sepsis. J Trans/ Med 2009, 7:28.

10. Baeke F, Takiishi T, Korf H, Gysemans C, Mathieu C: Vitamin D: modulator of the immune system. Curr Opin Pharmacol 2010, 10:482-496.

11. Sadeghi K, Wessner B, Laggner U, Ploder M, Tamandl D, Friedl J, Zügel U, Steinmeyer A, Pollak A, Roth E, Boltz-Nitulescu G, Spittler A: Vitamin D3 down-regulates monocyte TLR expression and triggers hyporesponsiveness to pathogen-associated molecular patterns. Eur J Immunol 2006, 36:361-370.

12. Equils O, Naiki Y, Shapiro AM, Michelsen K, Lu D, Adams J, Jordan S: 1,25-Dihydroxyvitamin D inhibits lipopolysaccharide-induced immune activation in human endothelial cells. Clin Exp Immunol 2006, 143:58-64

13. Horiuchi $H$, Nagata I, Komoriya K: Protective effect of vitamin D3 analogues on endotoxin shock in mice. Agents Actions 1991, 33:343-348.

14. Asakura H, Aoshima K, Suga Y, Yamazaki M, Morishita E, Saito M, Miyamoto K, Nakao S: Beneficial effect of the active form of vitamin D3 against LPSinduced DIC but not against tissue-factor-induced DIC in rat models. Thromb Haemost 2001, 85:287-290.

15. Moller S, Laigaard F, Olgaard K, Hemmingsen C: Effect of 1,25-dihydroxyvitamin D3 in experimental sepsis. Int J Med Sci 2007, 4:190-195.

16. Zhang Y, Leung DY, Richers BN, Liu Y, Remigio LK, Riches DW, Goleva E: Vitamin d inhibits monocyte/macrophage proinflammatory cytokine production by targeting MAPK phosphatase-1. J Immuno/ 2012 188:2127-2135

17. Khoo AL, Chai LY, Koenen HJ, Kullberg BJ, Joosten I, van der Ven AJ, Netea MG: 1,25-dihydroxyvitamin D3 modulates cytokine production induced by Candida albicans: impact of seasonal variation of immune responses. $J$ Infect Dis 2011, 203:122-130.

18. Nelson CD, Reinhardt TA, Beitz DC, Lippolis JD: In vivo activation of the intracrine vitamin $D$ pathway in innate immune cells and mammary tissue during a bacterial infection. PLoS One 2010, 5:e15469.

19. Hewison M: Antibacterial effects of vitamin D. Nat Rev Endocrino/ 2011 $7: 436$

20. Kamen DL, Tangpricha V: Vitamin D and molecular actions on the immune system: modulation of innate and autoimmunity. J Mol Med (Berl) 2010, 88:441-450

21. Liu PT, Stenger S, Li H, Wenzel L, Tan BH, Krutzik SR, Ochoa MT, Schauber J, Wu K, Meinken C, Kamen DL, Wagner M, Bals R, Steinmeyer A, Zügel U, Gallo RL, Eisenberg D, Hewison M, Hollis BW, Adams JS, Bloom BR, Modlin RL: Toll-like receptor triggering of a vitamin $\mathrm{D}$-mediated human antimicrobial response. Science 2006, 311:1770-1773

22. Nijnik A, Hancock RE: The roles of cathelicidin LL-37 in immune defences and novel clinical applications. Curr Opin Hemato/ 2009, 16:41-47.

23. Yim S, Dhawan P, Ragunath C, Christakos S, Diamond G: Induction of cathelicidin in normal and CF bronchial epithelial cells by 1,25-dihydroxyvitamin D(3). J Cyst Fibros 2007, 6:403-410.

24. Hertting $\mathrm{O}$, Holm A, Luthje $\mathrm{P}$, Brauner $\mathrm{H}$, Dyrdak $\mathrm{R}$, Jonasson AF, Wiklund $\mathrm{P}$ Chromek M, Brauner A: Vitamin D induction of the human antimicrobial Peptide cathelicidin in the urinary bladder. PLoS One 2010, 5:e15580.

25. Hodgin KE, Moss M: The epidemiology of sepsis. Curr Pharm Des 2008, 14:1833-1839

26. Ginde AA, Mansbach JM, Camargo CA Jr.: Association between serum 25-hydroxyvitamin $\mathrm{D}$ level and upper respiratory tract infection in the Third National Health and Nutrition Examination Survey. Arch Intern Med 2009, 169:384-390.

27. Sabetta JR, DePetrillo P, Cipriani RJ, Smardin J, Burns LA, Landry ML: Serum 25-hydroxyvitamin $d$ and the incidence of acute viral respiratory tract infections in healthy adults. PLoS One 2010, 5:e11088.

28. Laaksi I, Ruohola JP, Mattila V, Auvinen A, Ylikomi T, Pihlajamaki H: Vitamin D supplementation for the prevention of acute respiratory tract infection: a randomized, double-blinded trial among young Finnish men. $J$ Infect Dis 2010, 202:809-814.

29. Li-Ng M, Aloia JF, Pollack S, Cunha BA, Mikhail M, Yeh J, Berbari N: A randomized controlled trial of vitamin D3 supplementation for the prevention of symptomatic upper respiratory tract infections. Epidemiol Infect 2009, 137:1396-1404.

30. Wayse V, Yousafzai A, Mogale K, Filteau S: Association of subclinical vitamin $D$ deficiency with severe acute lower respiratory infection in Indian children under 5 y. Eur J Clin Nutr 2004, 58:563-567.

31. Karatekin G, Kaya A, Salihoglu O, Balci H, Nuhoglu A: Association of subclinical vitamin $D$ deficiency in newborns with acute lower respiratory infection and their mothers. Eur J Clin Nutr 2009, 63:473-477.

32. Roth DE, Shah R, Black RE, Baqui AH: Vitamin D status and acute lower respiratory infection in early childhood in Sylhet, Bangladesh. Acta Paediatr 2010, 99:389-393.

33. Roth $D E$, Jones $A B$, Prosser $C$, Robinson JL, Vohra S: Vitamin D status is not associated with the risk of hospitalization for acute bronchiolitis in early childhood. Eur J Clin Nutr 2009, 63:297-299.

34. McNally JD, Leis K, Matheson LA, Karuananyake C, Sankaran K, Rosenberg AM: Vitamin D deficiency in young children with severe acute lower respiratory infection. Pediatr Pulmonol 2009, 44:981-988.

35. Manaseki-Holland S, Oader G, Isag Masher M, Bruce J, Zulf Mughal M, Chandramohan D, Walraven G: Effects of vitamin D supplementation to children diagnosed with pneumonia in Kabul: a randomised controlled trial. Trop Med Int Health 2010, 15:1148-1155.

36. Urashima M, Segawa T, Okazaki M, Kurihara M, Wada Y, Ida H: Randomized trial of vitamin D supplementation to prevent seasonal influenza $A$ in schoolchildren. Am J Clin Nutr 2010, 91:1255-1260.

37. Lee P, Eisman JA, Center JR: Vitamin D deficiency in critically ill patients. NEngl J Med 2009, 360:1912-1914

38. Pittas AG, Dawson-Hughes B: Vitamin D and diabetes. J Steroid Biochem Mol Biol 2010, 121:425-429.

39. Van den Berghe G, Van Roosbroeck D, Vanhove P, Wouters PJ, De Pourcq L, Bouillon R: Bone turnover in prolonged critical illness: effect of vitamin D. J Clin Endocrinol Metab 2003, 88:4623-4632

40. Melamed ML, Michos ED, Post W, Astor B: 25-hydroxyvitamin D levels and the risk of mortality in the general population. Arch Intern Med 2008, 168:1629-1637.

41. Finklea JD, Grossmann RE, Tangpricha V: Vitamin D and chronic lung disease: a review of molecular mechanisms and clinical studies. Adv Nutr 2011 2:244-253

42. Amrein K, Venkatesh B: Vitamin D and the critically ill patient. Curr Opin Clin Nutr Metab Care 2012, 15:188-193.

43. Braun A, Chang D, Mahadevappa K, Gibbons FK, Liu Y, Giovannucci E, Christopher KB: Association of low serum 25-hydroxyvitamin D levels and mortality in the critically ill. Crit Care Med 2011, 39:671-677.

44. Braun AB, Gibbons FK, Litonjua AA, Giovannucci E, Christopher KB: Low serum 25-hydroxyvitamin $D$ at critical care initiation is associated with increased mortality. Crit Care Med 2012, 40:63-72.

45. Venkatram S, Chilimuri S, Adrish M, Salako A, Patel M, Diaz-Fuentes G: Vitamin $D$ deficiency as associated with mortality in the medical intensive care 
unit. Crit Care 2011, 15:R292.

46. Flynn L, Zimmerman LH, McNorton K, Dolman M, Tyburski J, Baylor A, Wilson $\mathrm{R}$, Dolman H: Effects of vitamin D deficiency in critically ill surgical patients. Am J Surg 2012, 203:379-382.

47. Cecchi A, Bonizzoli M, Douar S, Mangini M, Paladini S, Gazzini B, Degl'innocenti S, Linden M, Zagli G, Peris A: Vitamin D deficiency in septic patients at ICU admission is not a mortality predictor. Minerva Anestesiol 2011,77:1184-1189.

48. Ginde AA, Camargo CA Jr., Shapiro Nl: Vitamin D insufficiency and sepsis severity in emergency department patients with suspected infection. Acad Emerg Med 2011, 18:551-554.

49. Bjelakovic G, Gluud LL, Nikolova D, Bjelakovic M, Nagorni A, Gluud C: Meta-analysis: antioxidant supplements for liver diseases - the Cochrane Hepato-Biliary Group. Aliment Pharmacol Ther 2010, 32:356-367.

50. Krishnan A, Ochola J, Mundy J, Jones M, Kruger P, Duncan E, Venkatesh B: Acute fluid shifts influence the assessment of serum vitamin $D$ status in critically ill patients. Crit Care 2010, 14:R216.

51. Kouroumichakis I, Papanas N, Proikaki S, Zarogoulidis P, Maltezos E: Statins in prevention and treatment of severe sepsis and septic shock. Eur J Intern Med 2011, 22:125-133.

52. Yavuz B, Ertugrul DT, Cil H, Ata N, Akin KO, Yalcin AA, Kucukazman M, Dal K, Hokkaomeroglu MS, Yavuz BB, Tutal E: Increased levels of 25 hydroxyvitamin $D$ and 1,25-dihydroxyvitamin $D$ after rosuvastatin treatment: a novel pleiotropic effect of statins? Cardiovasc Drugs Ther 2009, 23:295-299.

53. Perez-Castrillon JL, Vega G, Abad L, Sanz A, Chaves J, Hernandez G, Duenas A: Effects of Atorvastatin on vitamin $D$ levels in patients with acute ischemic heart disease. Am J Cardio/ 2007, 99:903-905.

54. Martin GS, Mannino DM, Eaton S, Moss M: The epidemiology of sepsis in the United States from 1979 through 2000. NEngl J Med 2003, 348:1546-1554.

55. Barnato AE, Alexander SL, Linde-Zwirble WT, Angus DC: Racial variation in the incidence, care, and outcomes of severe sepsis: analysis of population, patient, and hospital characteristics. Am J Respir Crit Care Med 2008, 177:279-284.
56. Esper AM, Moss M, Lewis CA, Nisbet R, Mannino DM, Martin GS: The role of infection and comorbidity: factors that influence disparities in sepsis. Crit Care Med 2006, 34:2576-2582.

57. Mayr FB, Yende S, Linde-Zwirble WT, Peck-Palmer OM, Barnato AE, Weissfeld $L A$, Angus DC: Infection rate and acute organ dysfunction risk as explanations for racial differences in severe sepsis. JAMA 2010, 303:2495-2503.

58. Grant WB, Peiris AN: Possible role of serum 25-hydroxyvitamin D in blackwhite health disparities in the United States. J Am Med Dir Assoc 2010, 11:617-628.

59. Chen TC, Chimeh F, Lu Z, Mathieu J, Person KS, Zhang A, Kohn N, Martinello S, Berkowitz R, Holick MF: Factors that influence the cutaneous synthesis and dietary sources of vitamin D. Arch Biochem Biophys 2007, 460:213-217.

60. Danai PA, Sinha S, Moss M, Haber MJ, Martin GS: Seasonal variation in the epidemiology of sepsis. Crit Care Med 2007, 35:410-415.

61. Maxwell JD: Seasonal variation in vitamin D. Proc Nutr Soc 1994, 53:533-543.

62. Bischof $M G$, Heinze $G$, Vierhapper $H$ : Vitamin $D$ status and its relation to age and body mass index. Horm Res 2006, 66:211-215.

63. Amrein K, Sourij H, Wagner G, Holl A, Pieber TR, Smolle KH, Stojakovic T, Schnedl C, Dobnig H: Short-term effects of high-dose oral vitamin D3 in critically ill vitamin $\mathrm{D}$ deficient patients: a randomized, double-blind, placebo-controlled pilot study. Crit Care 2011, 15:R104.

64. Mata-Granados JM, Vargas-Vasserot J, Ferreiro-Vera C, Luque de Castro MD Pavón RG, Quesada Gómez JM: Evaluation of vitamin D endocrine system (VDES) status and response to treatment of patients in intensive care units (ICUs) using an on-line SPE-LC-MS/MS method. J Steroid Biochem Mol Biol 2010, 121:452-455.

doi:10.1186/cc11252

Cite this article as: Kempker JA, et al.: Vitamin D in sepsis: from basic science to clinical impact. Critical Care 2012, 16:316. 